\title{
ORNAMEN GIGI BALANG PADA KEMASAN KEMBANG GOYANG SEBAGAI CIRI KHAS BETAWI
}

\author{
Titi Dwi Latufah ${ }^{1)}$, Rike Phuspita Sari ${ }^{2)}$, Puji Anto ${ }^{3)}$ \\ Program Studi Desain Komunikasi Visual, \\ Fakultas Bahasa dan Seni, Universitas Indraprasta Jakarta PGRI \\ J1. Nangka 58 C Tanjung Barat, Jakarta Selatan, 12530, Indonesia
}

titi.dwi.latufah@gmail.com

\begin{abstract}
Abstrak
Dalam upaya mengenalkan kembang goyang sebagai camilan khas betawi, kemasan pada produk kembang goyang dibuat sedemikian rupa untuk menonjolkan ciri khas Betawi. Ciri tersebut dapat menjadi identitas tanda visual agar konsumen dapat mengenali tanda visual sebagai ciri khas Betawi sehingga terciptanya daya ingat. Metode penelitian yang digunakan aadalah deskriptif kualitatif. Desain yang dibuat tidak semata-mata tanpa dasar, desain yang dibuat harus mengikuti trend desain yang sedang disukai oleh khalayak umum agar timbul ketertarikan dalam membeli produk. Selain itu, desain yang dibuat harus mempunyai kesan sederhana, bertujuan untuk memudahkan konsumen mengingat desain kemasan tersebut.
\end{abstract}

Kata Kunci: ciri budaya, tanda visual, daya ingat

\begin{abstract}
In an effort to introduce kembang goyang as a typical Betawi snack, the packaging on the kembang goyang product is made in such a way as to highlight the characteristic Betawi. These characteristics can be a visual sign identity so that consumers can recognize visual signs as a Betawi characteristic so that memory is created. The research method used is a qualitative descriptive.The design is made not solely, the design created must include a design trend that is favored by consumers in order ro attract attention to buying product. In addition, the design made must also have a simple impression, which is designed to facilitate consumers who consider the packaging design.
\end{abstract}

Keywords: cultural characteristic, visual sign, memory

Correspondence author: Titi Dwi Latufah, titi.dwi.latufah@gmail.com, Jakarta, and Indonesia

This work is licensed under a CC-BY-NC

\section{PENDAHULUAN}

Di era globalisasi saat ini, fungsi kemasan tak lagi hanya sekadar sebagai pelindung produk saja, tetapi mampu menjadi salah satu alternatif sebagai media promosi serta mampu menciptakan daya ingat yang dihasilkan dari bentuk visual kemasan tersebut. Permasalahan yang 
terjadi saat ini adalah kemasan kembang goyang hanya terpacu pada produk yang ditonjolkan, tidak mampu membuahkan daya ingat pada benak konsumen sebagai ciri camilan khas betawi.

Menurut teori Santrock dalam memori atau ingatan adalah penyimpanan informasi di setiap waktu. Para psikolog pendidikan mempelajari bagaimana informasi pada awalnya ditempatkan, atau dikodekan menjadi ingatan, bagaimana informasi disimpan setelah dikodekan, dan bagaimana informasi ditemukan atau dipanggil kembali untuk tujuan tertentu diwaktu yang akan datang. Dengan kata lain, konsumen mampu mengingat kembang goyang sebagai camilan khas betawi dengan menonjolkan ciri tertentu yang terdapat pada kemasan, sehingga mampu membuahkan ingatan pada benak konsumen.

Untuk mengupas permasalahan yang terjadi saat ini, kami melakukan perancangan ornament gigi balang pada kemasan kembang goyang sebagai ciri khas Betawi dengan mengikuti desain masa kini yaitu flat design. Serta berpacu pada teori elemen desain yang tertera pada buku Mantra Kemasan Juara guna menciptakan daya ingat yang kuat pada kemasan kembang goyang.

\section{METODE PENELITIAN}

Metode yang digunakan dalam penelitian ini menggunakan metode deskriptif. Metode deskriptif adalah metode penelitin yang proses pengumpulan datanya memungkinkan peneliti untuk menghasilkan deskripsi tentang fenomena sosial yang diteliti. Dengan adanya data yang diperoleh, peneliti mampu mengidentifkasi mengapa, apa dan bagaimana fenomena itu terjadi.

Dari metode deskriptif tersebut peneliti akan menjelaskan bagaimana proses merancang ornamen Gigi Balang pada kemasan kembang goyang sebagai ciri khas Betawi. Proses pengumpulan data didapat dari buku, jurnal, dan mencari referensi ornamen maupun kemasan kue dari internet.

\section{HASIL DAN PEMBAHASAN Ornamen Gigi Balang}

Menurut Marjono dan Suyatno dalam (Supriyadi, 2006: 106), ornamen pada hakikatnya merupakan hiasan-hiasan yang terdapat pada suatu tempat disesuaikan dengan keserasian situasi dan kondisi. Sebagai karya seni, ornamen berarti hiasan yang bersifat indah. Oleh karena itu, seni onamen memiliki fungsi menghiasi suatu benda atau barang sehingga menjadikan benda atau barang itu tampak lebih atau bernilai indah, berharga, dan bermakna.

Menurut Sunaryo dalam (Supatmo, 2016: 111) sebagai karya seni, ornamen berarti hiasan yang bersifat indah. Oleh karena itu, seni onamen memiliki fungsi menghiasi suatu benda atau barang sehingga menjadikan benda atau barang itu tampak lebih atau bernilai indah, berharga, dan bermakna. Menurut Supatmo (2016: 111) pemakaian ornamen dimaksudkan untuk mendukung atau meningkatkan kualitas dan nilai estetis suatu benda atau karya manusia.

Ornamen Gigi balang termasuk dalam jenis ornamen inorganis yang mempunyai ciri khas bentuk dasar segitiga ke bawah dan persegi pangjang yang disubtraksi oleh bidang setengah lingkaran pada tepinya. Ornamen ini memiliki berbagai macam jenis, namun memiliki filosofi yang sama diantaranya adalah tumpal, wajik, wajik susun dua, potongan waru dan kuntum melati.

Menurut Guntur dalam (Meisar Ashari, 2013: 451), ornamen inorganis adalah ornamen yang mengambil bentuk yang berasal dari fenomena alam yang tidak hidup, yaitu seperti, awan, bintang, bulan, bunga, matahari, sungai, karang, dan lainnya. Ornamen gigi balang mengambil bentuk gunung, berupa segitiga (cagak) berdasarkan penjelasan dari Pergub Ikon Budaya Betawi, karena itu ornamen Gigi Balang termasuk ornamen inorganis.

Selain itu, ornamen Gigi Balang juga termasuk ornamen yang berada diluar ruangan atau eksterior. Menurut Supriyadi (2006: 108), ornamen eksterior berarti ornamen atau hiasan yang dipasang diluar bangunan dengan cara ditempel atau dilekatkan dan dapat memiliki fungsi dan nilai estetis bangunannya. Gigi Balang diletakan pada bagian atas bangunan atau listplang untuk menambah keindahan rumah (Nediari \& Hartanti, 2015: 373)

Berdasarkan Pergub Ikon Budaya Betawi, makna atau filosofi dari Ornamen Gigi Balang adalah sebagai perlambang gagah, kokoh dan berwibawa. Dari beberapa makna atau filosofi ini, pelambangan kokoh diambil karena ornamen Gigi Balang ini diterakan pada kemasan sehingga 
menggambarkan kesan kemasan yang kuat dan dapat melindungi isi kemasannya (Gubernur Provinsi Daerah Khusus Ibukota Jakarta, 2017: 4).

\section{Flat Design dan Redesign pada Ornamen Gigi Balang}

Menurut Anindita \& Riyanti (2016: 3), saat ini flat design atau desain datar banyak digunakan dalam karya desain komunikasi visual dan banyak perusahaan ternama yang menggunakan flat design dalam produk-produknya, seperti Microsoft, Apple, Google, Kompas, dan lain-lain. Flat design berkesan sederhana karena tidak menerapkan berbagai efek gradasi, bayangan, glossy dan lain-lain, dan karena itu pula flat design jauh terlihat berbeda dari gaya desain sebelumnya. Walaupun flat design sudah ada sejak 2010-an dan menjadi tren, flat design tetap berkembang dan banyak mempengaruhi karya-karya desainer hingga tahun-tahun kedepannya.

Terdapat empat elemen pada flat design, yaitu: 1. Ilustrasi, 2. Tipografi, 3. Tata letak, dan 4. Warna. Ilustrasi adalah gambar yang digunakan untuk menyampaikan pesan atau memberi penjelasan secara visual. Tipografi adalah menyusun huruf dengan menerapkan nilai desain namun tetap dapat dibaca. Tata letak adalah menentukan letak tiap material atau konten pada sebuah media dan mengatur letak pada media sesuai jenis media dan sifatnya (Anindita \& Riyanti, 2016: 3).

Karena ornamen Gigi Balang hanya berupa gambar, maka elemen yang digunakan hanya tiga, yaitu ilustrasi, tata letak, dan warna. Ilustrasi dari ornamen Gigi Balang untuk menyampaikan pesan jika ornamen Gigi Balang merupakan khas Betawi, sehingga pemakaian ornamennya pada kemasan menjelaskan jika produk kemasan merupakan produk khas betawi. Dari segi tata letak, penempatan ornamen Gigi Balang diletakkan pada bagian atas kemasan sesuai dengan penempatan ornamen aslinya pada rumah tradisional betawi. Untuk warnanya digunakan warna merah tua yang kontras dengan warna coklat muda yang merupakan warna dasar kemasan sehingga bentuk ornamen jelas terlihat.

Redesign terdiri dari dua kata, yaitu 're' berarti mengulang atau kembali dan 'design' berarti rancangan, jadi redesign berarti merancang ulang sesuatu yang ada (Nugroho, 2012: 10). Menurut Suhaedin \& Giri (2004: 26), penerapan redesign dapat berupa menggabungkan beberapa motif tradisional, membuat ornamen dari referensi yang sudah ada dan membentuknya menjadi desain baru, atau menerapkan ornamen pada media yang berbeda dari media yang biasa menggunakan ornamen tersebut.

Dalam redesign ornamen Gigi Balang, kami menggunakan ornamen Bigi Balang jenis kuntum melati karena bentuk ornamen tersebut merupakan icon dari jenis gigi balang yang lain dilansir dari website jakarta tourism.

Desain ulang yang terdapat pada penerapan ornamen, biasanya diterapkan pada bagian atas bangunan rumah tradisional Betawi diterapkan pada kemasan kue Kembang Goyang dan membuat bentuk ornamennya menjadi lebih sederhana dari contoh ornamen Gigi Balang yang menjadi referensi. Redesign ini dilakukan karena ornamen Gigi Balang dapat dimanfaatkan sebagai ciri khas Betawi pada kemasan kue Kembang Goyang. Berikut adalah gambar tahap perancangannya:

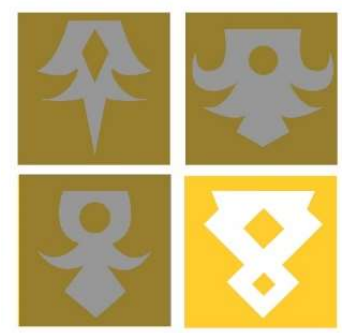

Gambar 1. Alternatif redesign ornamen gigi balang Sumber : Dokumen pribadi 
Gigi balang memiliki arti "kuat" dan mempresentasikan bentuk alam yaitu gunung. Maka dari itu, dipilih gambar keempat sebagai redesign ornamen gigi balang karena mempresentasikan bentuk gunung itu sendiri dan garis tegas lurus tanpa adanya lengkungan atau luwes menandakan kekuatan yang terkandung di dalam redesin ornamen gigi balang.

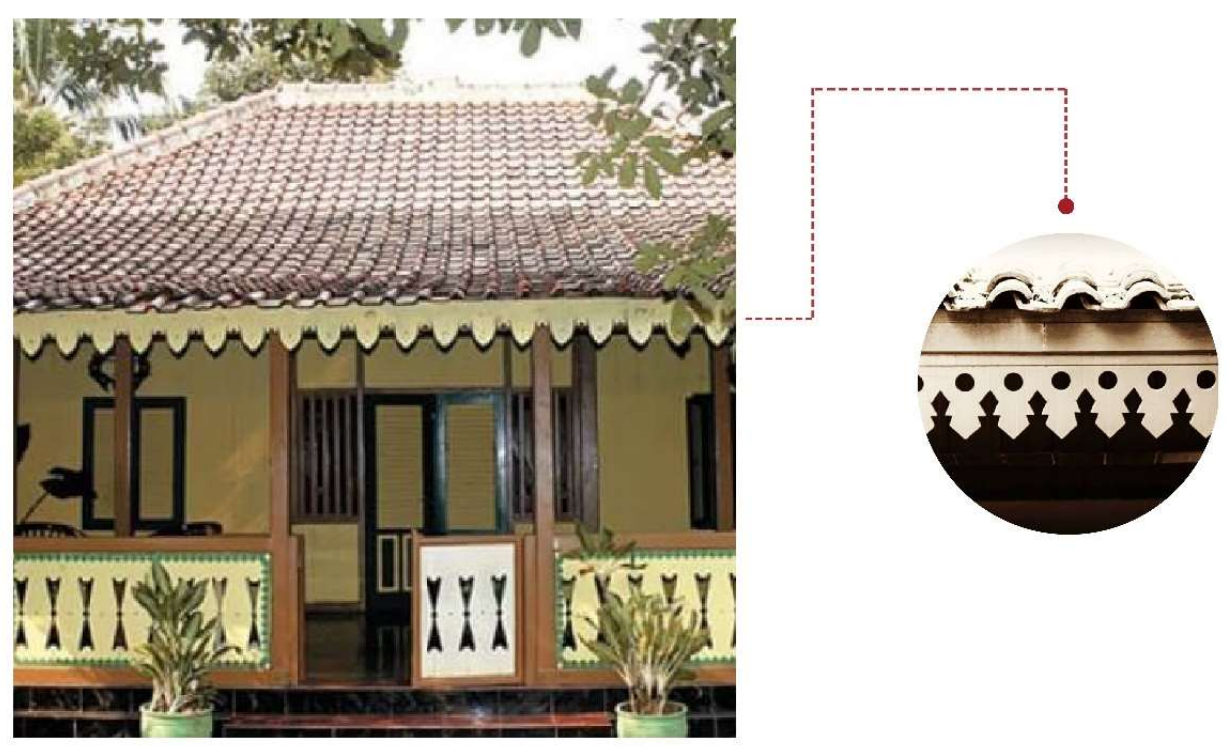

Gambar 2. Ornamen Gigi Balang pada rumah tradisional Betawi Sumber: https://ekbis.sindonews.com

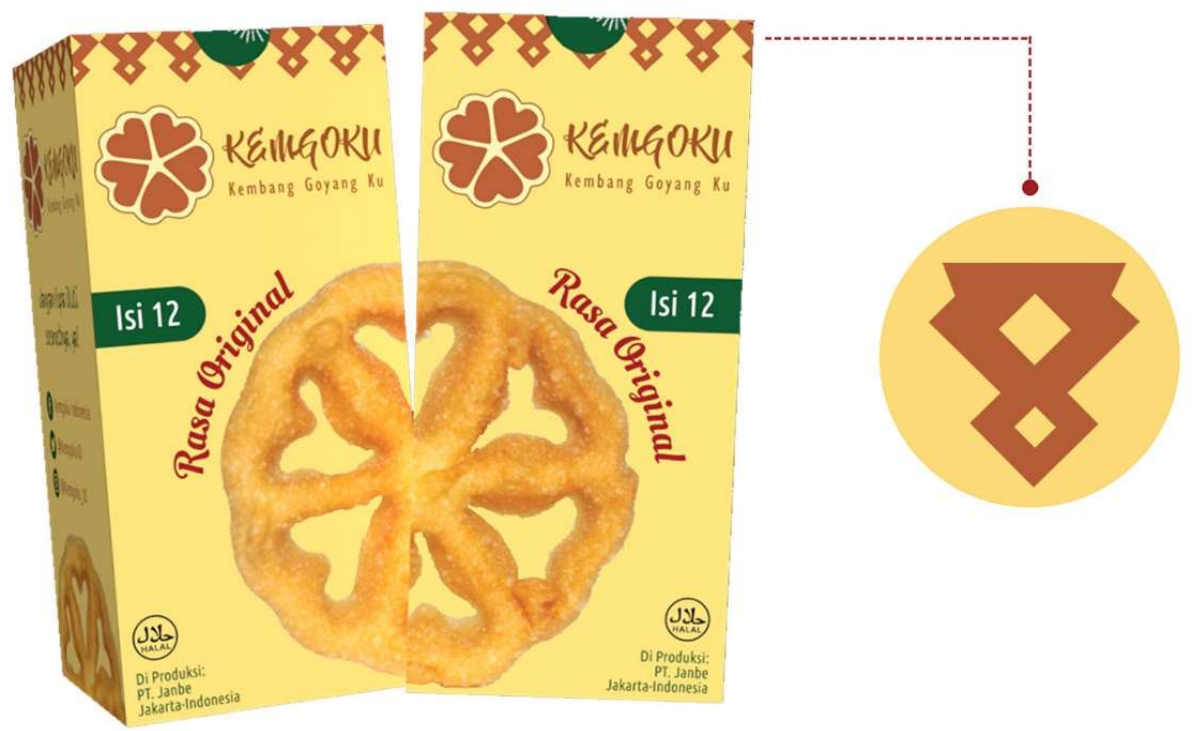

Gambar 3. Ornamen Gigi Balang pada kemasan kue Kembang Goyang Sumber: Dokumentasi pribadi 


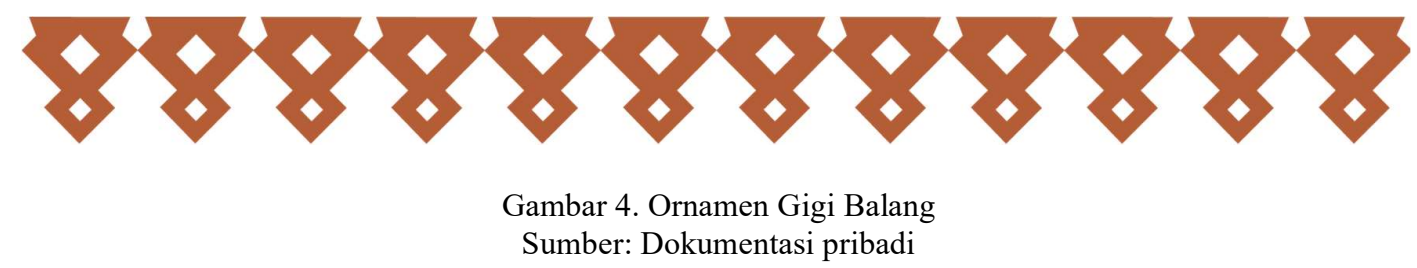

Ornamen redesign ini diletakan pada bagian atas kemasan yang memiliki peran sebagai hiasan sama halnya seperti ornamen gigi balang pada rumah betawi yang ditempatkan pada lisplang.

\section{SIMPULAN}

Kemasan tak hanya berfungsi sebagai pelindung produk, tetapi kemasan pada masa kini berfungsi sebagai sarana komunikasi serta menjadi daya tarik visual untuk menarik perhatian pembeli. Daya tarik tersebut mampu membuahkan ingatan dibenak konsumen mengenai ciri khas yang ada pada kemasan. Oleh karena itu, kami memanfaatkan hal tersebut dalam perancangan kemasan kue Kembang Goyang dengan menambahkan ornamen Gigi Balang yang terdapat pada bagian atas rumah atau lisplang pada bagian atas kemasan sebagai ciri khas betawi agar kemasan yang kami buat membuahkan daya ingat bahwa kue kembang goyang berasal dari suku Betawi.

Ornamen gigi balang yang telah di redesain berpacu pada desain yang digemari anak muda saat ini yaitu flat design. Selain karena berkesan sederhana, desain yang menggunakan flat design mudah untuk di ingat oleh konsumen karena tidak menerapkan berbagai efek gradasi, bayangan, glossy dan lain-lain. Selain itu, penerapan ornamennya yang biasanya diterapkan pada bagian atas bangunan rumah tradisional Betawi diterapkan pada kemasan kue Kembang Goyang sebagai ciri khas Betawinya

\section{DAFTAR PUSTAKA}

Anindita, M., \& Riyanti, M. T. (2016). Tren flat design dalam desain komunikasi visual. Dimensi $D K V, 1(1), 1-14$. Retrieved from https://www.trijurnal.lemlit.trisakti.ac.id/index.php/ seni /article/view/1816

Gubernur Provinsi Daerah Khusus Ibukota Jakarta. (2017). Peraturan Gubernur Provinsi Daerah Khusus Ibukota Jakarta (pp. 2-8). pp. 2-8. Retrieved from http://jakartatourism.go.id/2015/content/peraturan-gubernur-no11-tahun-2017-tentang-ikon-budayabetawi?language $=\mathrm{id}$

Ashari, M. (2013). Studi bentuk, Fungsi dan makna ornamen makam di kompleks makam rajaraja Bugis. Dewa Ruci, 8(3), 444-460. Retrieved from https://jurnal.isiska.ac.id/index.php/dewaruci/article/view/1135

Nediari, A., \& Hartanti, G. (2015). Pendokumentasian aplikasi ragam hias budaya Betawi pada desain interior ruang publik Café Betawi. Humaniora: Language, People, Art, and Communication Studies, 6(3), 367-381. https://doi.org/https://doi.org/10.21512 /humaniora.v6i3.3363

Nugroho, A. D. (2012). Redesign Kantor Wilayah Kementerian Agama Jawa Tengah. Retrieved from http://eprints.undip.ac.id/32397/

Suhaedin, E., \& Giri, P. (2004). Ragam hias kreasi. Retrieved from http://staff.uny.ac.id/sites/default/files/pendidikan/edin-suhaedin-purnama-girimpd/ragam-hias-kreasi-utuh.pdf 
Supatmo. (2016). Keragaman seni hias bangunan bersejarah Masjid Agung Demak. Imajinasi, $X(2), 107-120$. Retrieved from http://journal.unnes.ac.id/nju/index.php/imajinasi

Supriyadi, B. (2008). Kajian ornamen pada mesjid bersejarah kawasan pantura Jawa Tengah. ENCLOSURE, 7(2), 106-121. Retrieved from http://eprints.undip.ac.id/20159/ 